\title{
Editorial
}

\section{Editorial for Special Issue: New Advances of Cavitation Instabilities}

\author{
Florent Ravelet (D)
}

Citation: Ravelet, F. Editorial for Special Issue: New Advances of Cavitation Instabilities. Appl. Sci. 2021, 11, 5313. https://doi.org/10.3390/ app11125313

Received: 1 June 2021

Accepted: 4 June 2021

Published: 8 June 2021

Publisher's Note: MDPI stays neutral with regard to jurisdictional claims in published maps and institutional affiliations.

Copyright: (C) 2021 by the author. Licensee MDPI, Basel, Switzerland. This article is an open access article distributed under the terms and conditions of the Creative Commons Attribution (CC BY) license (https:/ / creativecommons.org/licenses/by/ $4.0 /)$.
Arts et Métiers Institute of Technology, CNAM, LIFSE, HESAM University, 75013 Paris, France; florent.ravelet@ensam.eu

Abstract: This editorial presents the main articles published in the Special Issue: New Advances of Cavitation Instabilities.

Keywords: water jet cavitation; cavitation peening; hydrodynamic cavitation; compressible two-phase flow; Kelvin-Helmholtz instability; slamming; vortex rope; bulb turbine; hydrofoil; Francis Turbine

Cavitation refers to the formation of vapor cavities in a liquid when the local pressure becomes lower that the saturation pressure [1]. In many hydraulic applications, cavitation is considered as a non-desirable phenomenon, as far as it may cause performance degradation, vibration problems, enhance broad-band noise-emission and eventually trigger erosion.

In this Special Issue, the deliberate use of cavitating jets for peening treatment of materials has been considered by Yoshimura et al. [2] and by Soyama [3]. This very interesting review shows how the aggressive intensity of a cavitating jet varies non-monotonically with the cavitation number in accordance with the variation of mixture sound speed for different regimes and that there exists an optimum.

These findings illustrate the importance of instabilities in cavitating flows. The cavitation is usually associated with flows with very high Reynolds numbers. This formally unsteady flow type is very sensitive to disturbances. In the ordinary case of a 2D profile, it is rightly recognized that for sufficiently low cavitation numbers, periodic or quasi-periodic cavity shedding arises. On more complex problems, like cavitation in inducers, several other periodical behaviors can emerge. Firstly, the local intrinsic flow instabilities will depend on the region that presents hydrodynamic cavitation: tip-leakage vortices, backflow vortices, or blades suction surface. Secondly, interaction between adjacent blades can lead to rotating instability, with cells of various sizes that propagate from blade to blade. Finally, system instabilities are also observed, because of the blockage linked to the volume variation of the pockets, or to a possible positive slope of the inducer characteristics linked to a change in the angle of attack on the blades. A more proper understanding of these instabilities is of crucial interest, especially in the field of turbomachinery, still motivating applied and fundamental research on cavitation instabilities.

In this Special Issue, Pipp et al. [4] and Ravelet et al. [5] present new findings in cloud shedding mechanisms arising in a $2 \mathrm{D}$ venturi geometry, respectively at very small scale (micro channel) and at at very low Reynolds numbers, where the development of the Kelvin-Helmholtz instability is evidenced. Viitanen et al. [6] studied numerically the cavitation dynamics on a standard hydrofoil with a compressible approach and a delayeddetached eddy simulation and show evidence of pressure wave fronts associated with a cavity cloud collapse. Pancirolli et al. [7] use a smooth particle hydrodynamics (SPH) model to study the cavity formation during the impact of a 2D wedge on a free surface and show that there is a threshold for the ratio between horizontal and vertical velocities above which a cavity is created, greatly impacting the stability of the body during slamming.

On a more applied point of view, Podnar et al. [8] improved the shape of an hydrofoil in order to reduce the cavitation development in a bulb turbine. Decaix et al. [9] conducted a comprehensive investigation on the importance of the time step tuning to achieve a good 
prediction on the cavitating behavior of a Francis Turbine. Finally, Li et al. [10] numerically explored the shape optimization of a globe valve in order to suppress cavitation inside of it.

Conflicts of Interest: The author declares no conflict of interest.

\section{References}

1. Brennen, C. Cavitation and Bubble Dynamics; Cambridge University Press: Cambridge, UK, 2013. [CrossRef]

2. Yoshimura, T.; Iwamoto, M.; Ogi, T.; Kato, F.; Ijiri, M.; Kikuchi, S. Peening Natural Aging of Aluminum Alloy by Ultra-HighTemperature and High-Pressure Cavitation. Appl. Sci. 2021, 11, 2894. [CrossRef]

3. Soyama, H. Cavitating Jet: A Review. Appl. Sci. 2020, 10, 7280. [CrossRef]

4. Pipp, P.; Hočevar, M.; Dular, M. Numerical Insight into the Kelvin-Helmholtz Instability Appearance in Cavitating Flow. Appl. Sci. 2021, 11, 2644. [CrossRef]

5. Ravelet, F; Danlos, A.; Bakir, F.; Croci, K.; Khelladi, S.; Sarraf, C. Development of Attached Cavitation at Very Low Reynolds Numbers from Partial to Super-Cavitation. Appl. Sci. 2020, 10, 7350. [CrossRef]

6. Viitanen, V.; Sipilä, T.; Sánchez-Caja, A.; Siikonen, T. Compressible Two-Phase Viscous Flow Investigations of Cavitation Dynamics for the ITTC Standard Cavitator. Appl. Sci. 2020, 10, 6985. [CrossRef]

7. Panciroli, R.; Minak, G. Cavity Formation during Asymmetric Water Entry of Rigid Bodies. Appl. Sci. 2021, 11, 2029. [CrossRef]

8. Podnar, A.; Hočevar, M.; Novak, L.; Dular, M. Analysis of Bulb Turbine Hydrofoil Cavitation. Appl. Sci. 2021, 11, 2639. [CrossRef]

9. Decaix, J.; Müller, A.; Favrel, A.; Avellan, F.; Münch-Alligné, C. Investigation of the Time Resolution Set Up Used to Compute the Full Load Vortex Rope in a Francis Turbine. Appl. Sci. 2021, 11, 1168. [CrossRef]

10. Li, J.; Gao, Z.; Wu, H.; Jin, Z. Numerical Investigation of Methodologies for Cavitation Suppression Inside Globe Valves. Appl. Sci. 2020, 10, 5541. [CrossRef] 